\title{
What Should be basis of Human Life? - Engineering, Economics or Ecology?
}

\author{
Prof. Prakash Gole, Founder, Ecological Society
}

Present article is based on Dubhashi Memorial Lecture titled "Significance of 3 Es", delivered by Prof. Gole in 2007 at Pune University. It is being published here due to its relevance to present modern life which is relying more and more on engineering, technology and economics (crony capitalism) while completely neglecting Ecology.

The 3 Es, Engineering, Economics and Ecology should be the basis of human life. But are they really? Indeed the first 2 Es definitely form the basis of modern life. Without engineering and technology modern life cannot be conceived. Also human beings are taken to be rational, objective. Self interest governs their actions and attitudes. Objectivity, not sentiments, is essential for the advancement of science. Economics therefore, which assumes rational human behaviour based on self-interest, rules human behaviour and social relations.

The third E, Ecology, however, lacks recognition. It seems invisible, is neither immediately felt nor readily identified. The general consensus is, Ecology is something extraneous, can either be totally dispensed with or replaced by technology. Human beings are or can become capable of producing every arrangement that nature has taken millions of years to produce through evolution. In India we already have a role model in sage Vishwamitra who threatened to produce exactly a parallel world.

The first 2 Es are therefore, considered enough for the survival and welfare of people, rational human beings technologically adequately equipped. Let as now analyse what the first 2 Es imply. Human beings started using engineering and technology ever since they used a stick to grab a fruit from a tree or to dig roots and tubers. But the real use of technology began when people started harnessing energy first fire, then fossil fuels like coal and peat, then hydro-electricity, oil and atomic energy. Technology essentially involves transformation of matter by using energy. As everyone knows matter and energy are governed by laws of thermodynamics. The first law states that matter and energy can neither be created nor destroyed. Energy is used not consumed. Energy is high grade when it is in a form with high availability to do applied work. All natural and technological physical processes proceed in such a way that the availability of energy involved, decreases. What is consumed when we use energy, then, is not energy itself but its availability to do useful work.

The second law of thermodynamics tells us that it is impossible to recycle energy and that eventually all energy will be converted into waste heat. Also it is impossible to recycle materials with $100 \%$ completeness. Some material is irrevocably lost in each cycle. If matter and energy cannot be created or destroyed, what does the economic process do? Matter and energy enter the economic process in a state of low entropy and comes out of it in a state of high entropy.

Any living organism fights the entropic degradation of its own material structure. Man's economic activity may transform a high entropy copper ore into a low entropy copper sheet but this lowering of entropy is more than compensated by increase in the entropy of the surroundings. In entropy terms the cost of any biological or economic enterprise is always greater than the product. In entropy terms any such activity necessarily results in a deficit.

The transformation of matter by energy, which is the essence of technology therefore, involves costs costs in terms of lost quantities of matter as 100\% transformation is impossible and costs in terms of energy passing into a state of unavailability; also these two things involve creation of waste leading to entropy of surroundings - a local cost in terms of pollution and garbage. Now if all these costs are taken into account, the cost of production of any commodity, where energy other than solar energy, is used, is higher than its value. Increase in production means increased costs. This is how the first $\mathrm{E}$ is intertwined with the second $\mathrm{E}$.

The economic effort is actually a dual effort. It aims 
at producing a surplus by keeping down costs. In nature however, surplus is produced without apparent costs by plants using solar energy. The use of solar energy through solar energy apparently considerably slows down the operation of the laws of thermodynamics. In photosynthesis food is synthesised for plants for their survival needs and additional food is produced for the survival needs of other organisms. Very little solar energy is passed out as waste heat and almost no waste is produced to increase the entropy of surroundings.

What evolution has produced is a closed system. Matter is recycled and energy is radiated without producing waste. Entropy in the surroundings is mainly through accidental happenings, sudden, natural events such as exceptional floods, fire, lightning, earthquakes, meteoric hits, droughts or failure of rain. Evolution continues its work of remediation and rehabilitation resulting in reduced entropy.

In such a system as costs are low so is the surplus. In a mature forest the net productivity is zero. Whatever is produced is consumed and/or recycled. Surplus is small and cannot be stored for a long time. All animals living in the forest are tuned to utilise this small surplus whenever it is available. The small amount of this surplus controls their populations and keeps them in balance with food supply. Ecology thus puts limits on the creation and maintenance of this surplus and controls population growth. Human beings can only increase the food supply and consequently human population by negating controls prescribed by ecology.

The relationship between the three Es can be explained as follows: Engineering and technology aim at increasing the amount of the surplus and make it as long lasting as possible; Economics prescribed and regulated the distribution of the surplus in such a way as to facilitate advances in technology and Ecology defines the limits to the creation of this surplus and awakens in human beings a desire to desist from the possible disastrous consequences of man's actions in increasing the surplus.

Surplus is only produced by negating the influence of ecology. Agriculture is the earliest human effort to produce a surplus. Essentially agriculture means a mono-culture contrary to poly-cultural arrangements existing in nature. The ecological control on agriculture is expressed in terms of pests that try to destroy crops. In promoting agricultural surplus people are still trying to overcome these controls either by using chemical weapons or by following rather than opposing ecological principles, as in organic farming. The gross amount of surplus increased enormously when people started using machines run on various forms of energy such as coal, oil and electricity. Ecological controls were not immediately apparent as they appeared as social costs. As emissions and effluents were freely discharged in the atmosphere or rivers, the pollution so caused was borne by the society as a whole. Private costs were kept low through monopoly on raw material sources, low wages, child labour and captive markets. Natural wealth of colonies in Asia and Africa was freely exploited and manufactured goods sold in those countries. The scale of production came to be increased enormously through the application of technology realizing the economies of scale. The post Second World War boom resulted in overexploitation, indeed ruthless exploitation of resources, especially non-renewable resources. The result was rapid depletion of accessible stocks and rise in social costs such as pollution and waste. The industrial society of USA was described by Prof. Galbraith as producing private affluence and public squalor. With the growth in the scale of production, ecological controls came to be felt as waste and pollution increased by leaps and bounds. This was the time (in the seventies of the last century ) when environtalism had its birth. It was an attempt by a few to make the majority aware of ecological controls and pay heed to them.

Industrialism which was the result of great advances in technology during the second world war, though global in character, may spawn its own anticlimax. One may even ask will it dig its own grave? At present industrialism, whose social incarnation is capitalism, is basking in its own triumph which resulted from the almost total annihilation of communism. But to make the surplus larger and more permanent, it must constantly search for cheaper and more accessible sources of raw material and energy and improve technology so as to reduce social costs, the so-called externalities, which costs have to be internalised due to pressures from the environmental lobby and legislation. This constant need to reduce costs (as scale is increased) results from the operation of laws of thermodynamics. Large-scale transformation of matter through the use of energy produces large-scale entropy, i.e. waste and pollution.

The need for reduction of costs calls for greater investments in raw materials, energy and improvements in technology. This calls for capital accumulation through savings which are made by concentrating wealth in ever fewer hands and if governments make the investments, by depriving the 
majority of many necessities of life like good education, health, sanitation, fuel, fodder and shelter. In less developed nations it also involves destruction of natural capital on which the livelihood of many depends. Indeed the number of people in slums is a measure of the destruction of natural capital and the number of people in upper and middle classes is a measure of the population that can be supported by man-made capital! The need to reduce costs deprives people from having adequate purchasing power to make a living possible as creation of man-made capital has increased costs all round. Shrinkage of purchasing power leads to failure of demand which periodically plagues capitalism. One must realize the direct connection between poverty amelioration and existence of natural capital. The greater the amount of natural capital the less will be the poverty and the greater the amount of man-made capital the greater will be the poverty!

Deprivation of adequate purchasing power for the majority and greater inequity in distribution of income make a mockery of all the ideals that a free, capitalistic society is supposed to have!

In reality ecological controls are becoming manifest through these two forces. The so-called developed countries are trying to thwart them through improvements in technology and greater access to available energy and resources. Technology requires great investment which becomes readily available during a war effort. One wonders whether it is in the interests of advanced technological nations to fan the fire of wars so that they can justify to their people greater investments in technology which always come at the expense of peoples' welfare.

The tragedy is that the less developed countries are trying to follow the same model, i.e. larger scales of production, greater and ruthless exploitation of natural resources, higher entropy of surroundings, greater inequality of incomes and lack of purchasing power for the majority. Higher investments in technology and production are possible by denying a majority of people education, health, sanitation, fuel, fodder, shelter and clothing. The apparent prosperity and wealth that is seen in certain pockets, in rural and urban areas is due to mining and liquidation of stocks of natural resources : air, water, soil, forest and marine wealth. The figures speak for themselves. Almost $50 \%$ of the land area lies in various degrees of degradation; most of the rivers lack fresh water flows and are actually sewers; natural forests cover smaller area each year though plantation monoculture has increased; there are 86 threatened mammals in India as against 76 in
China though in land area China is far larger than our country; there are 1236 threatened plant species in India as against only 312 in China. It seems that ecological controls are being negated by deliberately destroying ecology, the very foundation of our life. All people are not unaware of the impending crisis. There are efforts and movements to counter centralisation of power, to make the production of surplus more people-oriented, use soft technologies and restore degraded eco-systems. Watershed development, eco-system approaches and restoration are being used to promote environmental awareness and ecological rehabilitation.

All these may prove mere palliatives and not cures. A much more holistic approach is required. Only then will the promotion of greed inherent in the present system because of periodic failure of demand, be replaced by saner and judicious management of resources and markets. There should be a conscious effort to recognise ecological needs and to allocate adequate resources for them. In effect we must recognise the importance of and the necessity to bring back the operation of ecological controls. This is essential to control the greed of a few and satisfy the needs of many. The imperatives to achieve this are :

1. Decentralisation of planning: local resources used to satisfy local needs. Watershed development, the present local developmental effort, should not only aim at increasing the surplus but satisfying the basic needs of all. Basic needs include besides food, clean air, potable water, health and sanitation, adequate education, fuel, fodder, timber and other biomass etc. To provide these it is necessary to keep these resources in good shape ; i.e. restoration and qualitative improvement of atmosphere, water(stream), soil, vegetation etc. in other words to allocate resources for eco-system functioning. Agricultural production should be planned and market at village level. Though land remains individually owned, its utilization, i.e. crop pattern, water use should be planned by the village as a whole.

2. Landscape approach in planning: planning of the use of resources based on geographic and geomorphic features, soil and lie of the land, climate and vegetation. The aim should be welfare individuals in a particular landscape. Thus agriculture need not be taken into account.

3. Avoid settlement and other "brown uses" on agriculturally good soil.

4. Restoration of degraded eco-systems, especially compensatory restoration to be made compulsory to all major and medium projects; the focus has to be on 
restoration of natural capital.

5. Rejuvenation and revival of local and indigenous varieties of crops, fruit, fibres, domestic animals breeds and their marketing on a village or a group of village basis. The idea is to develop specialties at local level and to that extent frees villages from the middlemen. Also to encourage service and processing of produce at the village level.

6. The basic idea is to restrict the scale of production in such a way as to provide minimum resources for the production of intermediate goods. Such abstinence and restriction of ostentatious and orgiastic consumption can be possible with universal, correctly designed, holistic education. It should emphasize inter-relationships between various disciplines and should not erect unbreakable walls between them.
Ecological research will have to be the foundation of this system. Technology has to change its direction and content. Soft technology seems to be essential for providing welfare to all sundry. Technology should facilitate rather than obstruct and replace the essential ecological services and processes. Replacement is costly and will have side effects.

The welfare of the individual should be the prime concern and not of the economic system. In all fields and areas, today's policies seem to favour the market and the economic system and not the individual. Dreams of a strong and powerful India can be realised not by augmenting the GNP or by increasing the growth rate from 3 to $13 \%$ but by making individual citizens educated, enlightened, responsible, work conscious, healthy and happy. 